\title{
Preparation and Microstructure Analysis of TiC-Derived Carbons with Hierarchical Pore Structure
}

\author{
Jin Jia, Aiguo Zhou, Yuanyuan Zhu, Jiang Liu, Shihao Feng, Yufan Tao, \\ Baoling Xing, and Chuanxiang Zhang \\ School of Materials Science and Engineering, Henan Polytechnic University, Jiaozuo, Henan 454000, China \\ Correspondence should be addressed to Aiguo Zhou; zhouag@hpu.edu.cn
}

Received 30 January 2015; Accepted 10 April 2015

Academic Editor: Margarida Amaral

Copyright (C) 2015 Jin Jia et al. This is an open access article distributed under the Creative Commons Attribution License, which permits unrestricted use, distribution, and reproduction in any medium, provided the original work is properly cited.

Carbide-derived carbons (CDCs) with hierarchical pore structure are prepared from commercial TiC powders by chlorination at temperature range of $600-1100^{\circ} \mathrm{C}$. As-synthesized CDCs mainly consist of amorphous carbon and there exists a graphitization trend at chlorinating temperature above $800^{\circ} \mathrm{C}$. If chlorinating temperature is below $1000^{\circ} \mathrm{C}, \mathrm{CDC}$ particles maintain the shape of original TiC particles. Above $1000^{\circ} \mathrm{C}$, obvious cracks appear in CDC particles and some particles are broken into small parts. The specific surface area (SSA) of CDCs is in the range from $672 \mathrm{~m}^{2} / \mathrm{g}$ to $1609 \mathrm{~m}^{2} / \mathrm{g}$. The highest SSA is $1609 \mathrm{~m}^{2} / \mathrm{g}$ for CDC chlorinated at $1000^{\circ} \mathrm{C}$. Most pores in these CDCs are micropores with the size of $0.7-2 \mathrm{~nm}$. However, some mesopores and macropores also exist.

\section{Introduction}

Carbide-derived carbons (CDCs) are produced from carbides by removing noncarbon elements in the process of high temperature chlorination. CDCs with tunable pore size have numerous actual and potential applications in the area such as supercapacitors [1, 2], lubrication [3], hydrogen/methane storage [4], and electrode materials [5].

Generally, the pore size of CDCs is continuously distributed in a small range. Recently, it is found that carbons with hierarchical pore (HP) structure have higher performance than general carbons with monosize pore structure in the area of energy storage $[6,7]$. These HP carbons have micropores, mesopores, and/or macropores. A hierarchical and highly porous $\mathrm{CDC}$ is obtained by chlorination from mesostructured $\mathrm{SiC} / \mathrm{TiC}[8,9]$ ceramics or preceramic polymer [10]. CDCs with micro-, meso-, and/or even macropores show high gas uptake and excellent performance as electrode materials in supercapacitors [11-14].

Is it possible to make CDCs with hierarchical pore structures (HPCDCs) directly from dense monolithic carbide precursor by high temperature chlorination? In this paper, an attempt is made to synthesize HPCDCs by chlorination from dense TiC.

Titanium carbide $(\mathrm{TiC})$ is one of the most common and widely used carbides to make CDCs $[15,16]$. Small and uniform carbon-carbon distance of $\mathrm{TiC}$ leads to uniform porosity and narrow pore size distribution of obtained CDCs. Their specific surface area (SSA) and total pore volume increase as chlorination temperature increases from $600^{\circ} \mathrm{C}$ to $900^{\circ} \mathrm{C}$; however, the pore size distributions are almost unchanged [17]. Additionally, the fabrication of HPCDCs by chlorination from mesoporous TiC was studied $[8,18]$.

In this study, CDCs are prepared from commercial dense titanium carbides by high temperature chlorination. Similar synthesis is reported in previous literature [17]. However, in our opinion, further microstructure study can help us better understand the material and the synthesis process. Although scanning electron microscopy (SEM) cannot be used to observe micropores in CDCs, it can clearly observe the surface morphology of CDC particles. In this paper, CDCs with meso- and macropores are desired. Extensive SEM pictures, combined with the results of X-ray diffraction (XRD) and Raman spectroscopy, are used to study the surface morphology of CDC particles. 


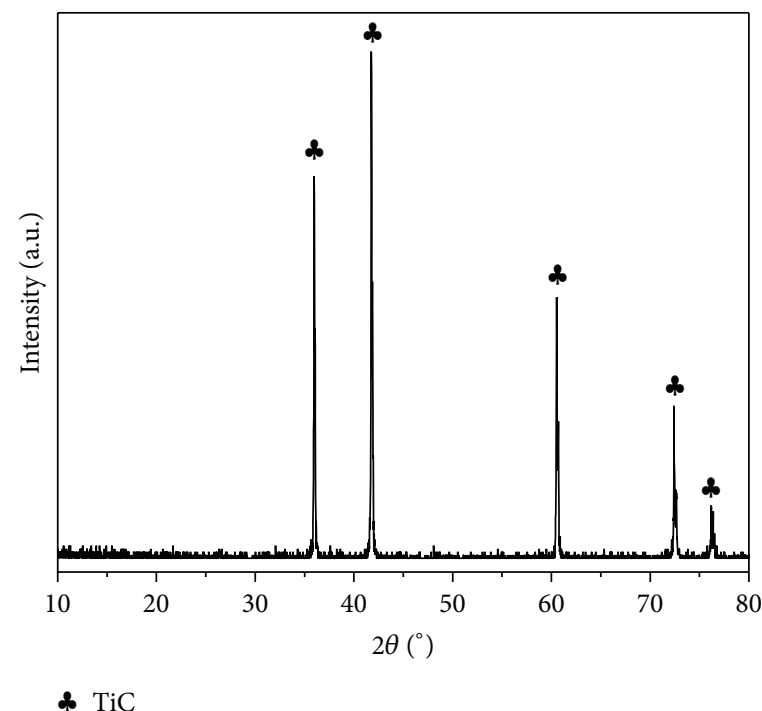

(a)

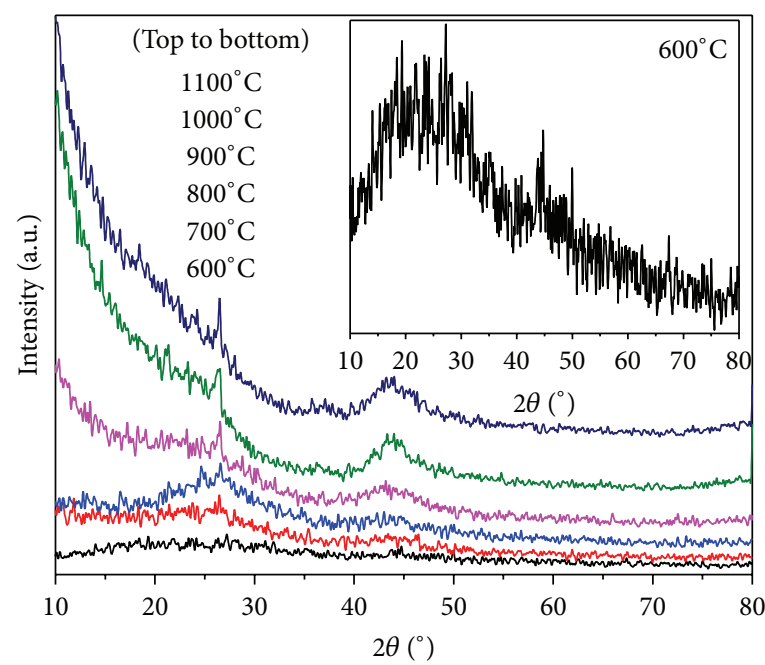

(b)

FIGURE 1: (a) XRD patterns of $\mathrm{TiC}$ and (b) CDC samples synthesized at various temperatures. Complete conversion of TiC to carbon takes place at $600^{\circ} \mathrm{C}$ and above. Broad peaks show the highly amorphous nature of the carbon produced from TiC.

\section{Experimental}

2.1. Preparation. CDCs were produced by chlorination from commercial TiC powders $(2-4 \mu \mathrm{m}, 99 \mathrm{wt} . \%$ pure, Aladdin Industrial Co., China). The TiC powders were placed on a graphite foil and loaded in the effective hot zone of a horizontal quartz tube furnace. The tube was purged with Ar for $30 \mathrm{~min}\left(60 \mathrm{~cm}^{3} / \mathrm{min}\right)$ and then heated up to the desired temperature $\left(600-1100^{\circ} \mathrm{C}\right)$ at a rate of $20^{\circ} \mathrm{C} / \mathrm{min}$. Once the desired temperature was reached and stabilized, the flowing Ar was stopped and a chlorinating process for $3 \mathrm{~h}$ began in freshly prepared $\mathrm{Cl}_{2}$ gas. After the chlorinating process completed, the samples were cooled down to room temperature under flowing Ar atmosphere $\left(10-60 \mathrm{~cm}^{3} / \mathrm{min}\right)$ to remove residual metal chlorides and then taken out for further analyses. A description of the chlorination process in detail can be found elsewhere [19].

2.2. Measurements. XRD patterns were obtained by X-ray diffractometer (XRD, Bruker AXS Co., Germany) based on $\mathrm{Cu} \mathrm{K}_{\alpha}$ radiation. Microstructure of CDC particles was observed by scanning electron microscope (SEM, JSM6390LV, JEOL, Japan). CDC samples were also analyzed by micro-Raman spectroscopy (Renishaw 1000, UK) using an Ar ion laser (wave length: $514.5 \mathrm{~nm}$, spot size: $2 \mu \mathrm{m}$ ) at 500 magnification. Isotherms of CDCs were measured by a $\mathrm{N}_{2}$ absorption apparatus at $77 \mathrm{~K}$ (Autosorb-iQ-MP, Quantachrome, USA). Before $\mathrm{N}_{2}$ sorption measurements, all samples were dried at $473.15 \mathrm{~K}$ for $10 \mathrm{~h}$ in vacuum. Brunauer Emmett Teller (BET) SSA was calculated by BET equation from volume of gas adsorbed at relative pressure between 0.05 and 0.3 , where the BET isotherm is linear. Pore size distribution (PSD) and SSA of CDCs, assuming slit pores, were evaluated by nonlocal density functional theory (NLDFT).
$V$ - $t$ method was used to obtain the plots of differential micropore area/volume versus synthesis temperature.

\section{Results and Discussion}

3.1. CDC Structure. Figure 1 shows the XRD patterns of raw material $\mathrm{TiC}$ and obtained CDCs. From the figure, all $\mathrm{TiC}$ transforms to carbon at temperature above $600^{\circ} \mathrm{C}$. The absence of sharp peaks in XRD patterns of CDCs (Figure 1(b)) indicates that as-synthesized CDCs are amorphous. However, it is noticed that there is a weak peak at $26^{\circ}$ for samples synthesized at temperature above $900^{\circ} \mathrm{C}$. The $26^{\circ}$ peak is the characteristic peak of graphite. Therefore, some amorphous carbons transform to graphite at temperature above $900^{\circ} \mathrm{C}$.

Figure 2 shows the Raman spectroscopy analysis results of as-synthesized CDCs. For perfectly ordered graphite, only one peak, $G$ band corresponding to in-plane stretching at $\sim 1579 \mathrm{~cm}^{-1}$, should be shown in the range studied in Figure 2(a). However, most graphites with disordered carbons generally exhibit a second disorder-induced peak (D band) at $\sim 1349 \mathrm{~cm}^{-1}$ as well as two combination bands (2D band at $\sim 2686 \mathrm{~cm}^{-1}$ and D + G band at $\sim 2914 \mathrm{~cm}^{-1}$ ) [20]. As shown in Figure 2(a), all samples show two main peaks, D and $\mathrm{G}$ bands of graphitic carbon. At chlorinating temperature of $600^{\circ} \mathrm{C}$, the carbons are just formed and in amorphous state. The corresponding D band and G band are weak as shown in Figure 2(a). As chlorinating temperature increases, both $\mathrm{D}$ band and $\mathrm{G}$ band become stronger and sharper obviously. $2 \mathrm{D}$ band and $\mathrm{D}+\mathrm{G}$ band appear at $800^{\circ} \mathrm{C}$ chlorinated samples and become stronger and sharper as chlorinating temperature increases to $1100^{\circ} \mathrm{C}$.

From the analysis of the position of D band and G band, it is found that $\mathrm{D}$ band shifts to low angle as temperature 


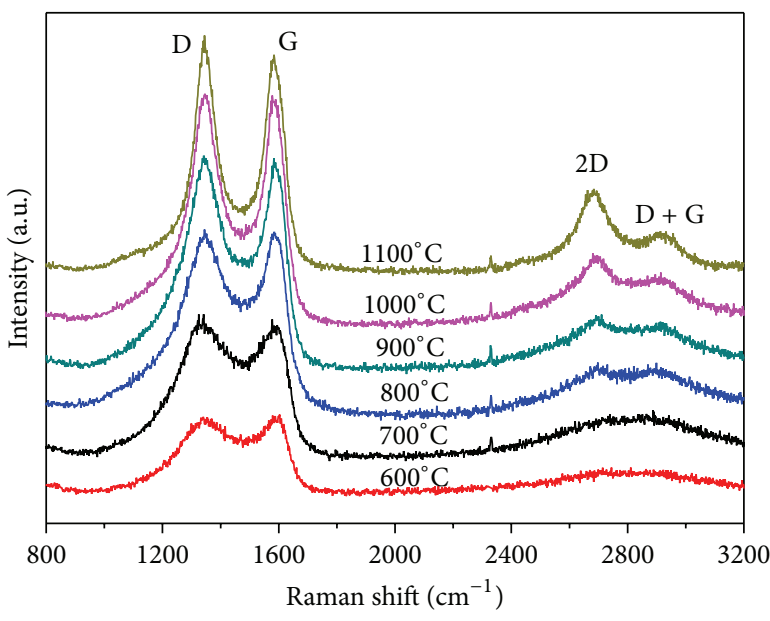

(a)

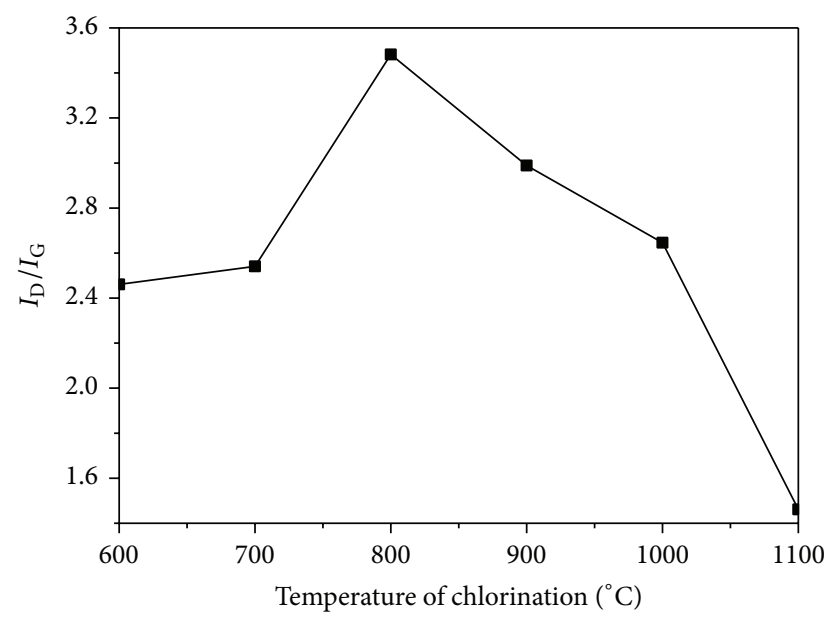

(c)

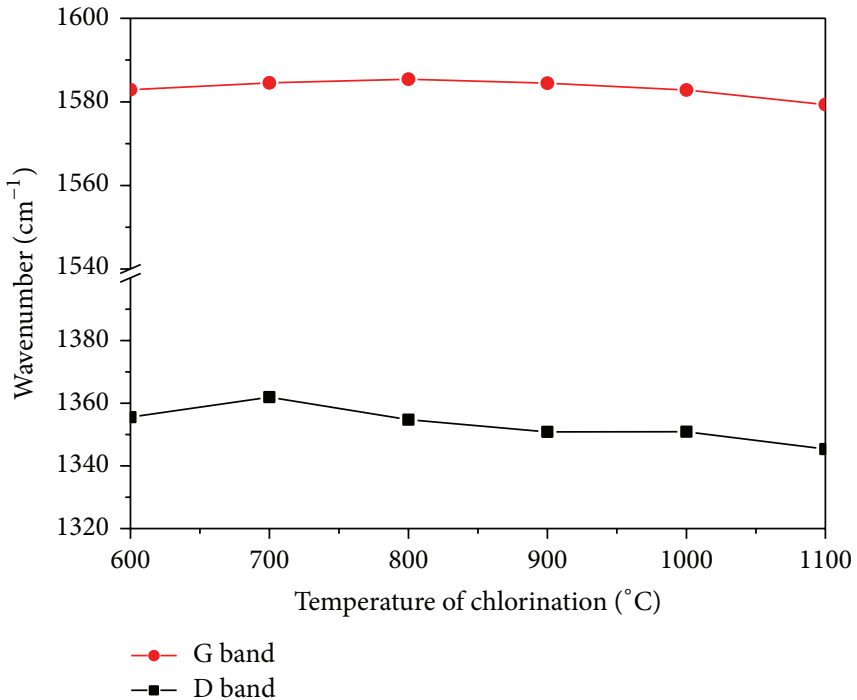

(b)

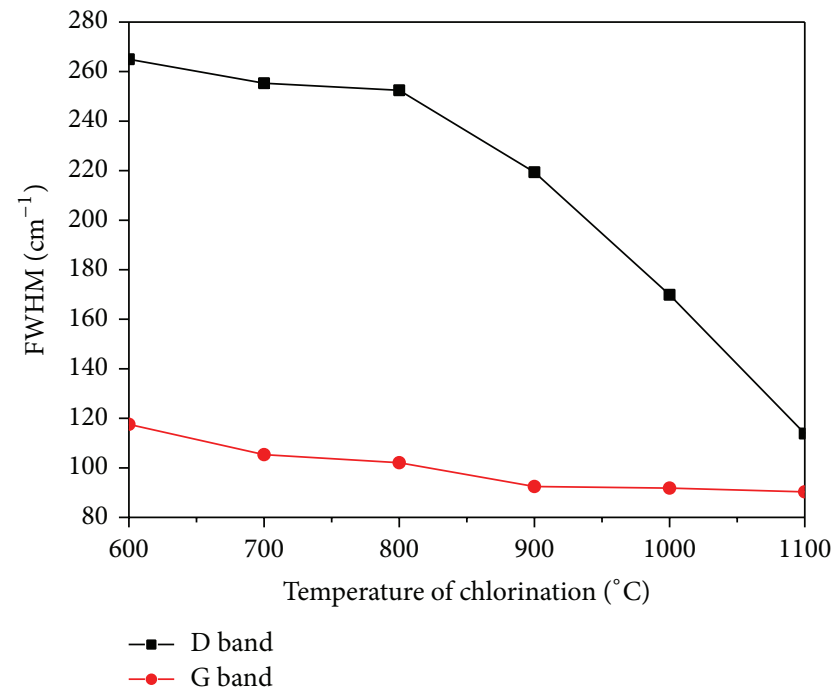

(d)

FIgURE 2: (a) Raman spectra of CDC produced by chlorinating TiC for 3 hours at $600-1100^{\circ} \mathrm{C}$. (b) Positions of D and G bands of carbon. (c) Ratio of integrated intensities of D and G bands. (d) Full width at half maximum (FWHM) of D and G bands.

increases, as illustrated in Figure 2(b), which should be due to lattice defects and/or $\mathrm{sp}^{2}$ hybridization of carbons. Figure 2(c) shows the intensity ratio of D band and $G$ band $\left(I_{\mathrm{D}} / I_{\mathrm{G}}\right.$, fitting calculation). Below $800^{\circ} \mathrm{C}$, it increases with reaction temperature, while, above $800^{\circ} \mathrm{C}$, the ratio decreases with temperature. Because $\mathrm{G}$ band is from ordered graphite and $\mathrm{D}$ band is from disordered graphite, the increase of $I_{\mathrm{D}} / I_{\mathrm{G}}$ below $800^{\circ} \mathrm{C}$ means more and more carbons in disordered state are formed; the decrease of $I_{\mathrm{D}} / I_{\mathrm{G}}$ above $800^{\circ} \mathrm{C}$ means more and more carbons transform from disordered state to ordered state. Figure 2(d) shows full width at half maximum of D band (FWHMD) and that of G band (FWHMG) for samples processed at varied temperature. As processing temperature increases, both FWHMs have a trend of decrease. This trend means the sharpening of the two bands, which indicates that more ordered CDCs are synthesized at higher temperatures.

Figure 3 shows the SEM images of TiC powders and synthesized CDC powders. Figure 3(a) is the SEM image of TiC particles. Figure $3(\mathrm{~b})$ is that of CDC particles processed at $600^{\circ} \mathrm{C}$. The surfaces of that $\mathrm{CDC}$ are rough; however, they exhibit no obvious pores or cracks. Compared with TiC particles (Figure 3(a)), CDC particles obtained at $600^{\circ} \mathrm{C}$ have similar particle shape (Figures 3(a) and 3(b)). For samples obtained at $700^{\circ} \mathrm{C}$, similar results are obtained. However, for samples made at $800^{\circ} \mathrm{C}$, some cracks appear on the surface of CDCs (Figure 3(c)). Moreover, more obvious cracks appear in the CDCs made at higher temperatures (Figures $3(\mathrm{~d})$ and $3(\mathrm{~g})$ ). Thus, the chlorinating process can result in the formation of intragranular cracks on the surface 


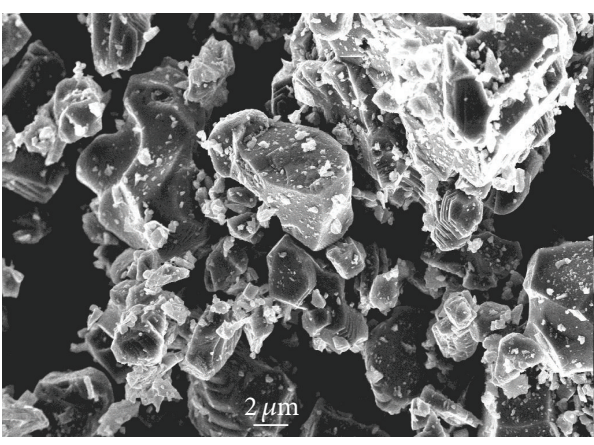

(a)

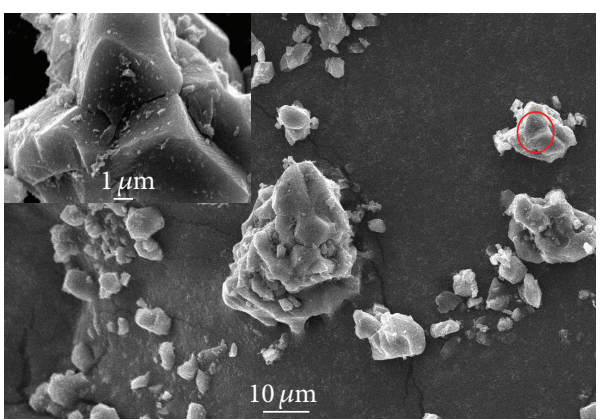

(c)

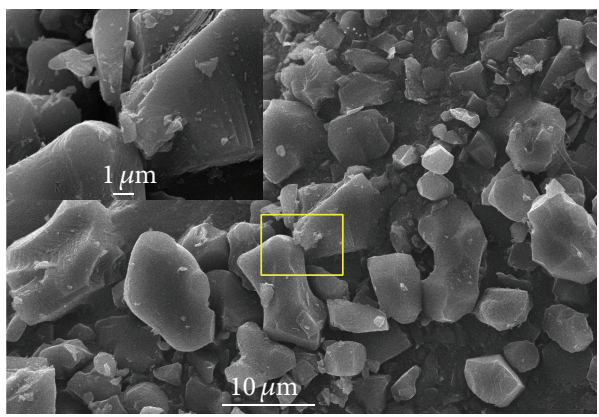

(e)

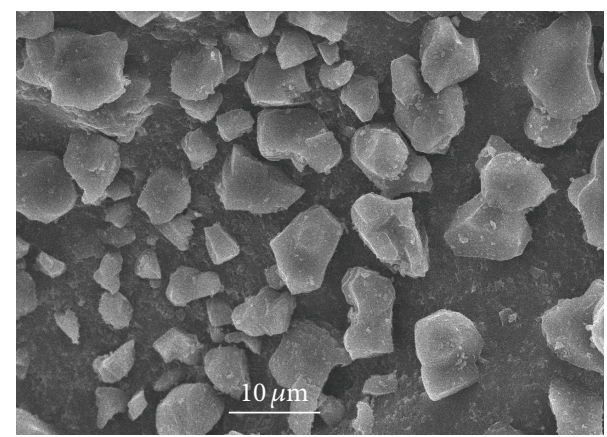

(b)

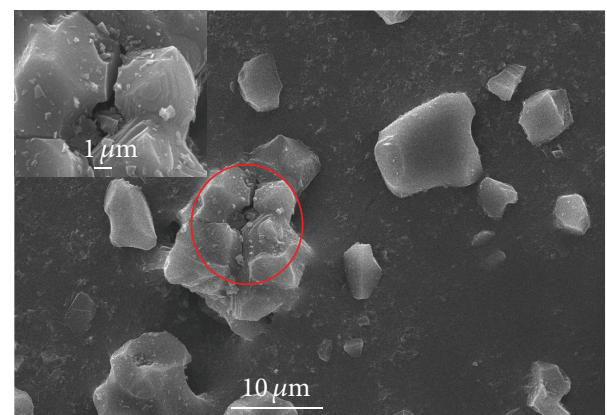

(d)

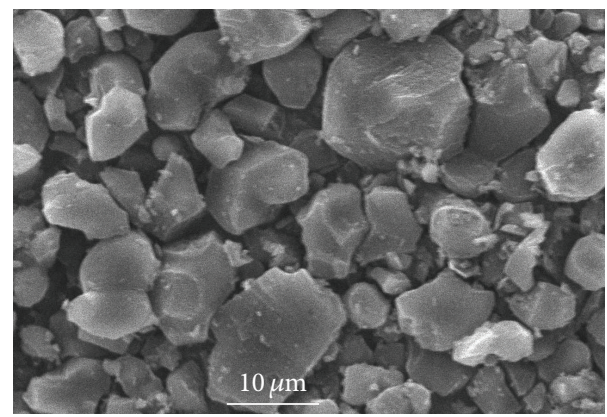

(f)

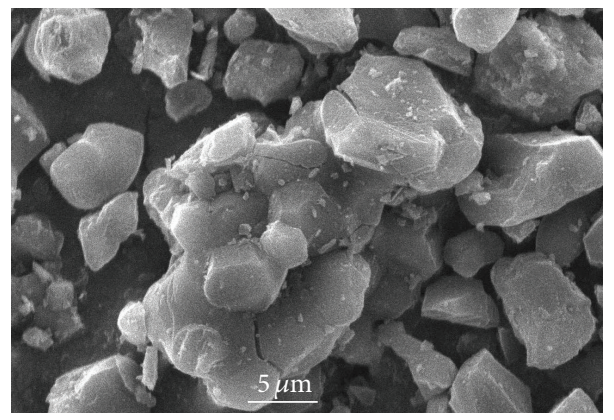

(g)

Figure 3: SEM images of (a) TiC powders before chlorination; (b) CDC chlorinated at $600^{\circ} \mathrm{C}$; (c) CDC chlorinated at $800^{\circ} \mathrm{C}$; $((\mathrm{d})$ and $(\mathrm{e}))$ $\mathrm{CDC}$ chlorinated at $900^{\circ} \mathrm{C}$; (f) $\mathrm{CDC}$ chlorinated at $1000^{\circ} \mathrm{C}$; and $(\mathrm{g}) \mathrm{CDC}$ chlorinated at $1100^{\circ} \mathrm{C}$.

of CDC particles, particularly in the CDCs produced at higher temperatures. The macroscopic shapes of obtained CDC particles are similar to that of $\mathrm{TiC}$ preformed during the chlorination below $1000^{\circ} \mathrm{C}$. However, above $1000^{\circ} \mathrm{C}$
(Figures 3(f) and 3(g)), the particles are broken into several small parts.

As the authors know, this is the first time to observe and report this phenomenon. There are two reasons for 


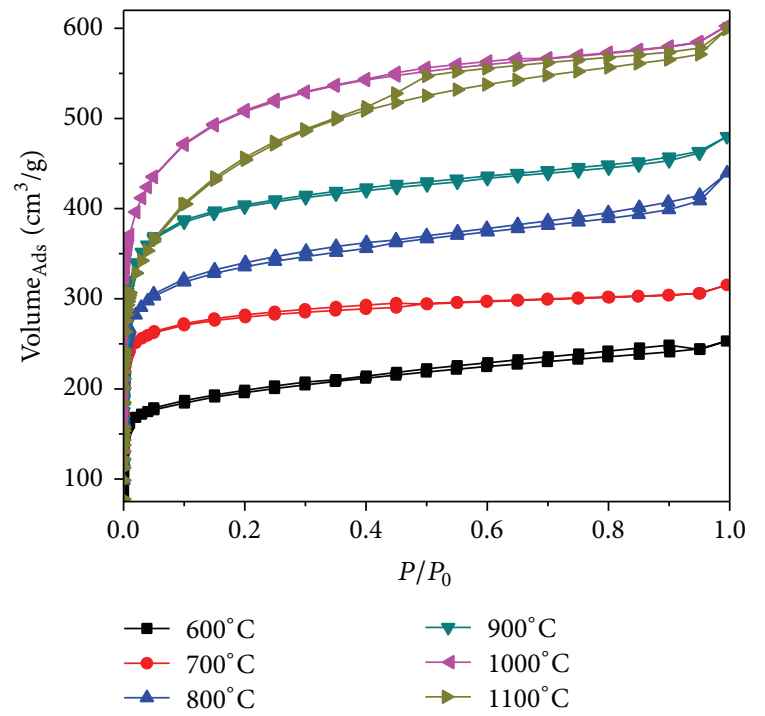

(a)

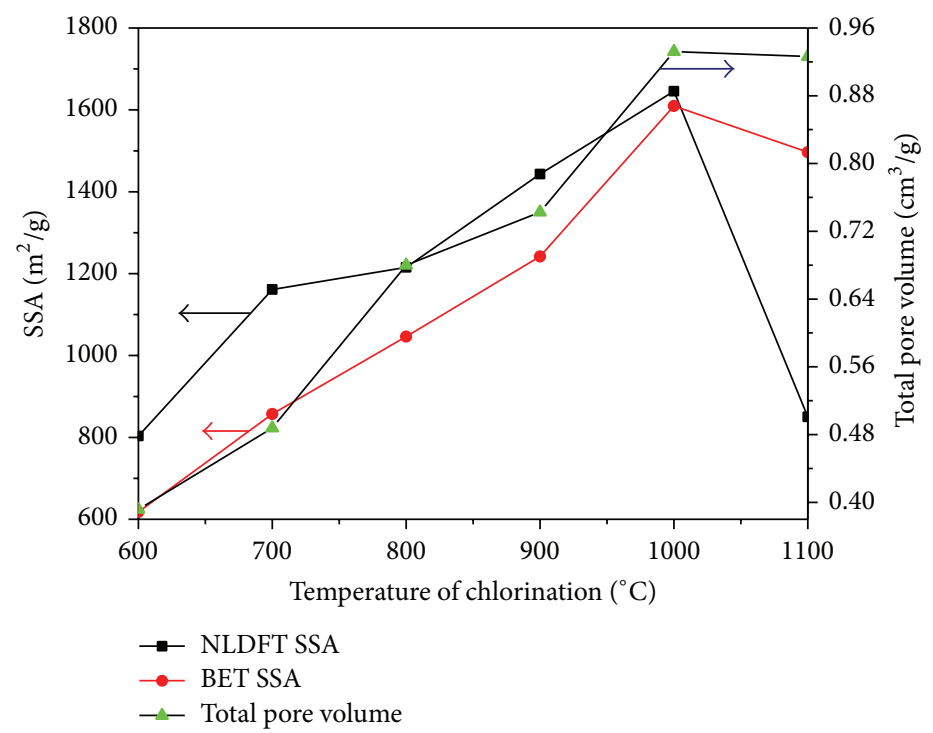

(b)

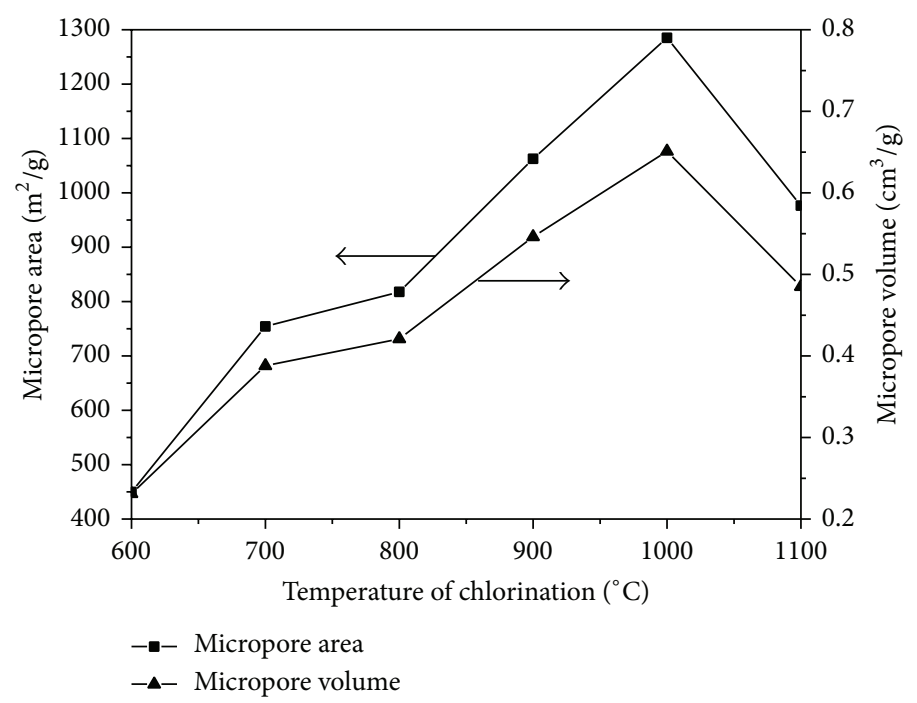

(c)

FIGURE 4: (a) $\mathrm{N}_{2}$ adsorption isotherms of CDCs. (b) Differential BET SSA, NLDFT SSA, and total pore volume versus the synthesis temperature plots. (c) Micropore area and micropore volume of CDCs.

the formation of these cracks. The first one is a chemical reason. At high temperature, Ti element in $\mathrm{TiC}$ particles is carried off by chlorination very fast, which results in the collapse of the just formed CDC structure, and in turn causes the formation of these cracks. The second one is a physical reason. Thermal stress generated during heating up and cooling down results in the cracks. The thickness of the cracks is up to $\sim 1 \mu \mathrm{m}$. These cracks are actually macropores that can act as molecule-buffer reservoirs and gas-channels in the energy storage application of CDCs.

As shown in Figure $3(\mathrm{~d})$, at $900^{\circ} \mathrm{C}$, there are some clear traces of graphitic layers in the surface of CDCs. Combining with XRD results (Figure 1) and Raman results (Figure 2), we drew the conclusion that the CDC changes from amorphous carbon to graphitic structure with increasing chlorination temperatures. Additionally, some pits are formed on the surface of CDCs made at $900^{\circ} \mathrm{C}$ (inset of Figure 3(e)). The formation of these pits should be related to the remotion of some carbons on the particle surface.

3.2. Specific Surface Areas and Pore Size Distributions. Isotherms of CDC samples are shown in Figure 4(a). A steep increase was observed at low relative pressure, followed by a moderate slope at intermediate pressure. Isotherms of all CDC samples, especially that of samples obtained at $700^{\circ} \mathrm{C}$, are linear (type I), which is the characteristic of isotherms of microporous materials (pore size less than $2 \mathrm{~nm}$ ). However, there exists small hysteresis, particularly in the isotherm of $1100^{\circ} \mathrm{C}$ sample, which is usually associated with mesopore structures (type H4); moreover, there are minor upwarps at 


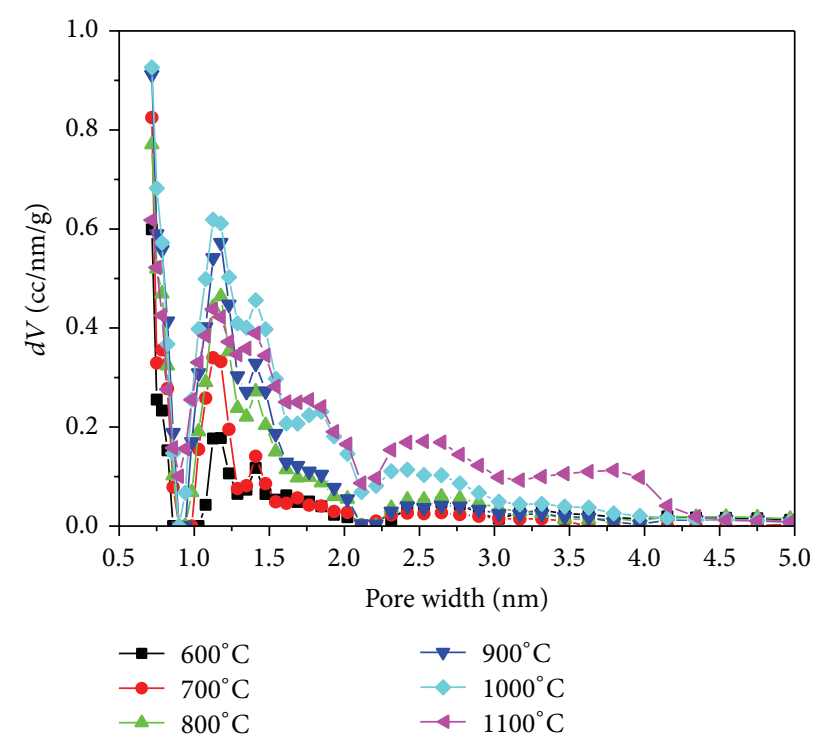

FIgURE 5: Pore size distributions of CDC samples.

the end of the isotherms of CDCs chlorinated at temperature above $800^{\circ} \mathrm{C}$, which are associated with macropores in the samples [21]. Therefore, CDCs prepared at $700^{\circ} \mathrm{C}$ have only micropores. However, as chlorinating temperature increased, small amount of mesopores and macropores appeared in CDCs. The isotherms of CDCs obtained at $800-1100^{\circ} \mathrm{C}$ exhibit the combined effects of the micropores, mesopores, and macropores in the CDCs. In combination with SEM images (Figure 3 ), the $\mathrm{N}_{2}$ isotherms of CDCs clearly support the evolving development of a multiscale pore structure from typical monosized microporous CDCs.

Figure 4(b) shows the SSA and pore volume of CDCs chlorinated at various temperature. BET SSA increases from $672 \mathrm{~m}^{2} / \mathrm{g}$ to $1609 \mathrm{~m}^{2} / \mathrm{g}$ with processing temperature if the temperature $<1000^{\circ} \mathrm{C}$. However, the value of BET SSA decreases if the temperature $>1000^{\circ} \mathrm{C}$. The largest BET SSA is $1609 \mathrm{~m}^{2} / \mathrm{g}$ at $1000^{\circ} \mathrm{C}$. The NLDFT SSA shows similar trend. And, total pore volume of CDCs increases with temperature at the range of $600-1000^{\circ} \mathrm{C}$ (Figure $4(\mathrm{~b})$ ); for $1100^{\circ} \mathrm{C}$ samples, the volume value decreases slightly. Figure 4(c) shows the different micropore area and micropore volume of CDCs chlorinated at varied temperature. Similar to the trends shown in Figure 4(b), both micropore area and volume increase and then decrease with temperature. The maximum values are obtained for $1000^{\circ} \mathrm{C}$ samples.

Figure 5 shows pore size distribution of CDC samples. The pore size of all CDC samples is mainly distributed in the range of $0.7-2 \mathrm{~nm}$. These are micropores that contribute maximized space sites for molecule storage or gas storage in the application of energy storage. However, there are some mesopores (2.0-4.5 nm) in CDCs as shown in Figure 5, and the amounts of mesopores increase with processing temperature. The distribution curves of CDC samples made at $700-900^{\circ} \mathrm{C}$ are not continuous and a gap exists in the range of 2.1-2.3 nm. Therefore, these CDCs have hierarchical pore structure. The mesopores are greatly significant for providing channels with lower gas-transport resistance and shorter diffusion routes.

In addition, as processing temperature increases, cumulative pore volume increases; however, the ratio of micropore/mesopore decreases and CDCs processed at higher temperatures contain more mesopores. The volume of micropores increases with temperature below $1000^{\circ} \mathrm{C}$ and decreases above $1000^{\circ} \mathrm{C} .1000^{\circ} \mathrm{C}$ is the best chlorinating temperature to acquire CDCs with the highest SSA (Figure 4(b)) and the largest micropore volume (Figure 4(c)).

In previous work [17], SSA and total pore volume increase as chlorination temperatures increase from $600^{\circ} \mathrm{C}$ to $900^{\circ} \mathrm{C}$. Here we report a maximum value at $1000^{\circ} \mathrm{C}$. Above $1000^{\circ} \mathrm{C}$, both SSA and pore volume decrease with temperature. This is because the increase of mesopore volume causes the decrease of micropore volume, and cracks appearing in the CDC (Figure 3) decrease the micropore volume further more. This is first report on the optimal chlorinating temperature, which is important for the production of CDCs with high SSA and large micropore volume.

Compared with previous method making HP CDCs from TiC with mesoporous structure [18], this is a simple and cheap method to produce HP CDCs directly from commercial TiC powders.

\section{Conclusions}

Hierarchically porous TiC-CDCs were successfully synthesized from commercially available titanium carbides via high temperature chlorination process and their microstructure, specific surface area, and pore size were analyzed. In the chlorinating process, CDCs with different microstructure were acquired by controlling the reaction temperature. The CDCs obtained in this experiment mainly consisted of amorphous carbon and maintained the shape of TiC particles. At $800^{\circ} \mathrm{C}$, the CDCs started transforming from amorphous carbon to graphite. As reaction temperature increased, the BET SSA increased from $672 \mathrm{~m}^{2} / \mathrm{g}$ to $1609 \mathrm{~m}^{2} / \mathrm{g}$. Furthermore, the chlorinating process can induce the formation of intragranular cracks (macropores) and pits on the surface of CDCs, particularly in the CDCs produced at higher temperatures such as $800^{\circ} \mathrm{C}$ and $1100^{\circ} \mathrm{C}$. As the authors know, it is the first time to observe and report this phenomenon.

\section{Conflict of Interests}

The authors declare that there is no conflict of interests regarding the publication of this paper.

\section{Acknowledgments}

The authors appreciate Professor Ruijun Zhang and Mr. Peng Chen for the help in building chlorinating equipment. This work is supported by Nature Science Foundation of China (51472075), Plan for Scientific Innovation Talent of Henan Province (134100510008), and Program for Innovative Research Team of Henan Polytechnic University (T2013-4). 


\section{References}

[1] P. Huang, M. Heon, D. Pech et al., "Micro-supercapacitors from carbide derived carbon (CDC) films on silicon chips," Journal of Power Sources, vol. 225, pp. 240-244, 2013.

[2] J. W. Campos, M. Beidaghi, K. B. Hatzell et al., "Investigation of carbon materials for use as a flowable electrode in electrochemical flow capacitors," Electrochimica Acta, vol. 98, pp. 123-130, 2013.

[3] J.-H. Jeong, H.-T. Bae, and D.-S. Lim, "The effect of iron catalysts on the microstructure and tribological properties of carbidederived carbon," Carbon, vol. 48, no. 12, pp. 3628-3634, 2010.

[4] S.-H. Yeon, I. Knoke, Y. Gogotsi, and J. E. Fischer, "Enhanced volumetric hydrogen and methane storage capacity of monolithic carbide-derived carbon," Microporous and Mesoporous Materials, vol. 131, no. 1-3, pp. 423-428, 2010.

[5] T. M. Arruda, M. Heon, V. Presser et al., "In situ tracking of the nanoscale expansion of porous carbon electrodes," Energy \& Environmental Science, vol. 6, no. 1, pp. 225-231, 2013.

[6] D.-W. Wang, F. Li, M. Liu, G.-Q. Lu, and H.-M. Cheng, "3D aperiodic hierarchical porous graphitic carbon material for highrate electrochemical capacitive energy storage," Angewandte Chemie International Edition, vol. 47, no. 2, pp. 373-376, 2008.

[7] S. J. Yang, T. Kim, J. H. Im et al., "MOF-derived hierarchically porous carbon with exceptional porosity and hydrogen storage capacity," Chemistry of Materials, vol. 24, no. 3, pp. 464-470, 2012.

[8] H.-J. Liu, J. Wang, C.-X. Wang, and Y.-Y. Xia, "Ordered hierarchical mesoporous/microporous carbon derived from mesoporous titanium-carbide/carbon composites and its electrochemical performance in supercapacitor," Advanced Energy Materials, vol. 1, no. 6, pp. 1101-1108, 2011.

[9] Y. Korenblit, M. Rose, E. Kockrick et al., "High-rate electrochemical capacitors based on ordered mesoporous silicon carbide-derived carbon," ACS Nano, vol. 4, no. 3, pp. 1337-1344, 2010.

[10] M. Oschatz, L. Borchardt, K. Pinkert et al., "Hierarchical carbide-derived carbon foams with advanced mesostructure as a versatile electrochemical energy-storage material," Advanced Energy Materials, vol. 4, no. 2, 2014.

[11] M. Oschatz, E. Kockrick, M. Rose et al., "A cubic ordered, mesoporous carbide-derived carbon for gas and energy storage applications," Carbon, vol. 48, no. 14, pp. 3987-3992, 2010.

[12] E. Kockrick, C. Schrage, L. Borchardt et al., "Ordered mesoporous carbide derived carbons for high pressure gas storage," Carbon, vol. 48, no. 6, pp. 1707-1717, 2010.

[13] S.-H. Yeon, P. Reddington, Y. Gogotsi, J. E. Fischer, C. Vakifahmetoglu, and P. Colombo, "Carbide-derived-carbons with hierarchical porosity from a preceramic polymer," Carbon, vol. 48, no. 1, pp. 201-210, 2010.

[14] M. Oschatz, L. Borchardt, M. Thommes et al., "Carbidederived carbon monoliths with hierarchical pore architectures," Angewandte Chemie International Edition, vol. 51, no. 30, pp. 7577-7580, 2012.

[15] Y. Gogotsi, A. Nikitin, H. Ye et al., "Nanoporous carbide-derived carbon with tunable pore size," Nature Materials, vol. 2, no. 9, pp. 591-594, 2003.

[16] V. Presser, L. Zhang, J. J. Niu et al., "Flexible nano-felts of carbide-derived carbon with ultra-high power handling capability," Advanced Energy Materials, vol. 1, no. 3, pp. 423-430, 2011.
[17] R. Dash, J. Chmiola, G. Yushin et al., “Titanium carbide derived nanoporous carbon for energy-related applications," Carbon, vol. 44, no. 12, pp. 2489-2497, 2006.

[18] G. Cheng, D.-H. Long, X.-J. Liu, and L.-C. Ling, "Fabrication of hierarchical porous carbide-derived carbons by chlorination of mesoporous titanium carbides," New Carbon Materials, vol. 24, no. 3, pp. 243-250, 2009.

[19] J. Xu, R. Zhang, S. Ge, J. Wang, Y. Liu, and P. Chen, "Effect of iron catalyst on the microstructure and electrochemical properties of vanadium carbide-derived carbons," Materials Chemistry and Physics, vol. 141, no. 1, pp. 540-548, 2013.

[20] A. C. Ferrari and J. Robertson, "Interpretation of Raman spectra of disordered and amorphous carbon," Physical Review B, vol. 61, no. 20, pp. 14095-14107, 2000.

[21] K. S. Sing, "Reporting physisorption data for gas/solid systems with special reference to the determination of surface area and porosity (Recommendations 1984)," Pure and Applied Chemistry, vol. 57, no. 4, pp. 603-619, 1985. 

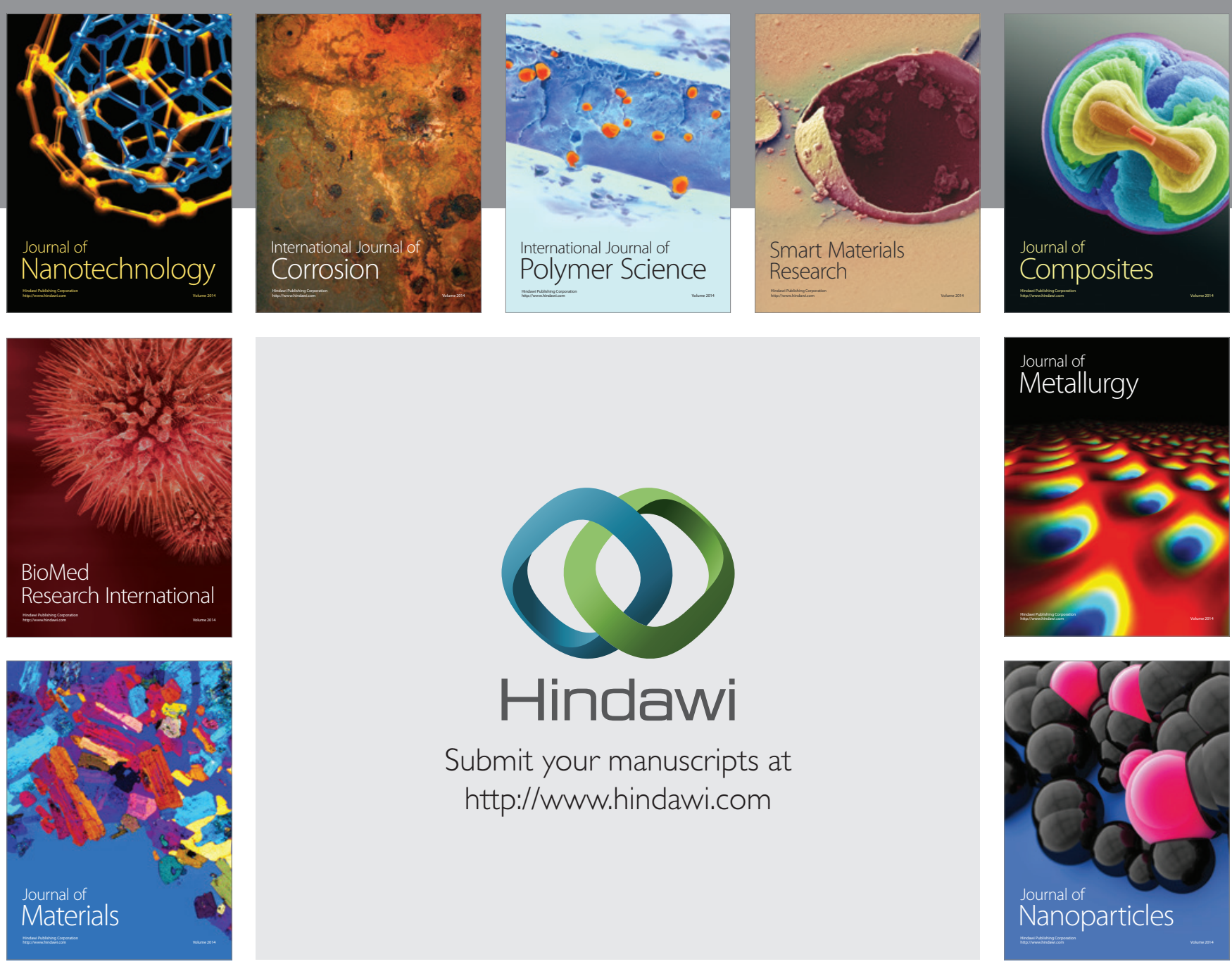

Submit your manuscripts at http://www.hindawi.com
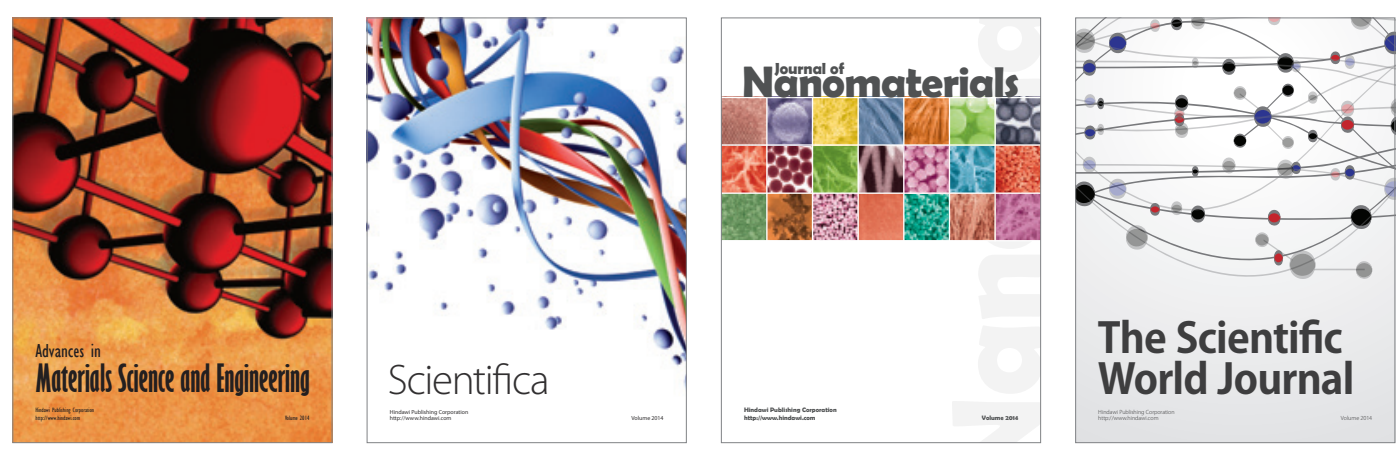

\section{The Scientific World Journal}
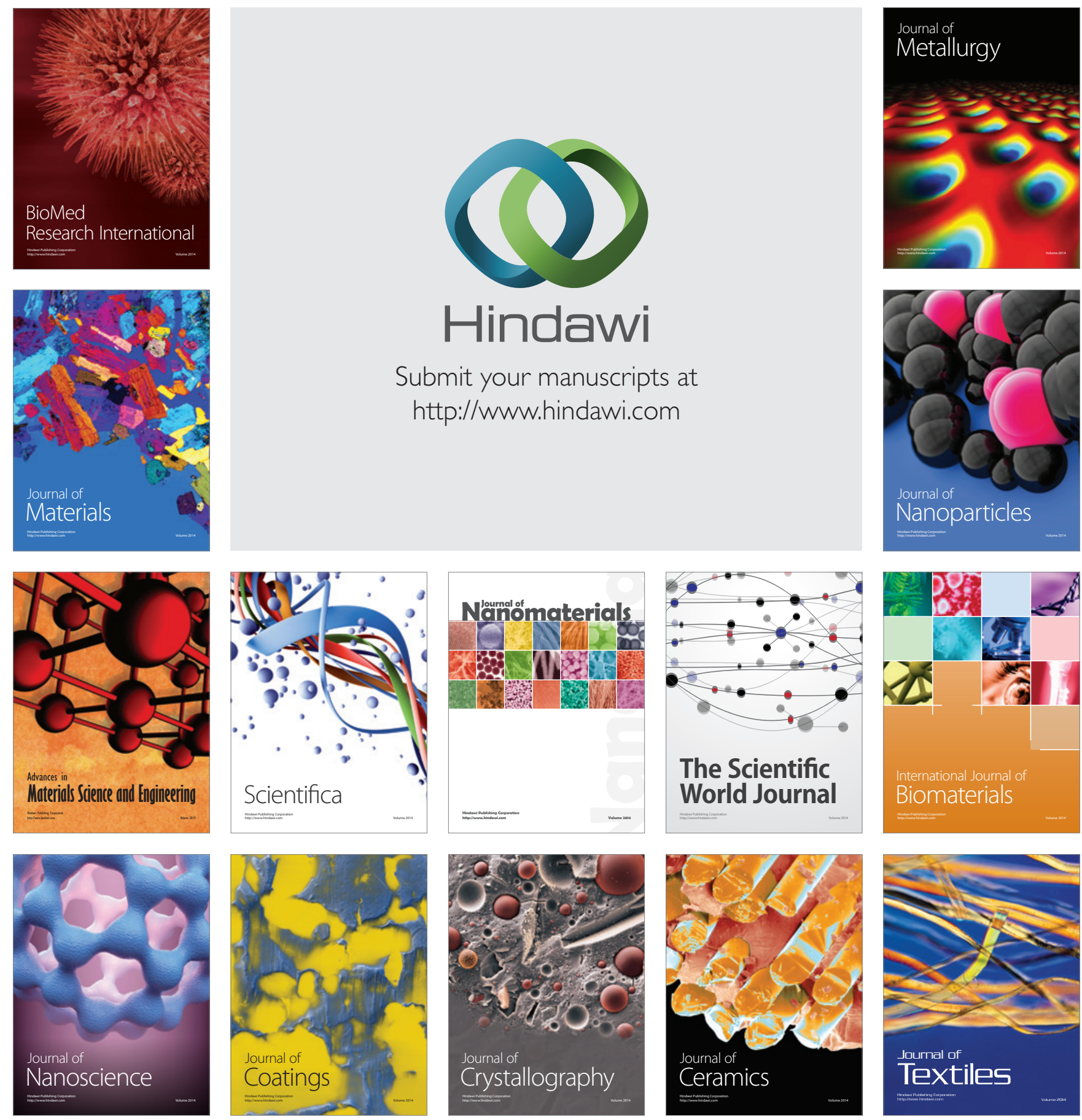